\title{
Unidad doméstica altoandina y crianza de camélidos sudamericanos
}

\author{
Teodomiro Palomino \\ teorunapa@hotmail.com \\ Departamento de Antropología, UNMSM
}

\begin{abstract}
Resumen
Para los habitantes altoandinos, la unidad doméstica es el espacio social en el que, con una mayor intimidad y un carácter central, reproducen sus condiciones de existencia. Al desencadenar este proceso e impulsarlo hacia otras unidades sociales concéntricamente mayores hace que todas sus manifestaciones acontezcan alrededor de la crianza de camélidos sudamericanos. El propósito de este artículo es dar cuenta de lo que la reproducción social altoandina representa cuando se procesa primordialmente, condición que no la exime a definir sus manifestaciones entre continuidades y rupturas, entre armonías y conflictos.
\end{abstract}

Palabras clave: Formación social, microregión, reproducción social, unidad doméstica y crianza.

\begin{abstract}
For Andean people, the household is the social space in which, with greater privacy and a central character, reproduces their conditions of existence. By unleasing this process and promote it to other concentrically higher social units makes that all its manifestations revolve around the breeding of camelidae south American. The purpose of this article is to account for what the social reproduction high Andean represent when processing primarily, condition that does not exempts to define its manifestations between continuities and ruptur, betweem harmony and conflict.
\end{abstract}

Key words: Social formation, microregion, social reproduction, household and breeding 


\section{Introducción}

Al culminar la década de los años 70, las llamas constituían la especie más importante entre los camélidos sudamericanos de la microrregión Occollo ${ }^{1}$. Desde entonces, hasta la actualidad, la especie a la que se atribuye la misma importancia es la de las alpacas. Este cambio relacionado a la población pecuaria originaria de la microrregión fue una postergada manifestación de una tendencia que cubrió prácticamente toda el área andina. Las llamas, según Bonavia, "a pesar de seguir siendo aprovechada en las comunidades serranas", han dejado de tener la importancia que tuvieron "en los tiempos prehispánicos o coloniales", ; y, las alpacas, según Flores Ochoa, de "ser animales con valor sólo para los pastores indígenas, refugiados en sus lejanas comunidades de la puna alta" han llegado a tener, gracias a la calidad de su fibra, un elevado valor comercial sin precedentes y muy favorables para los sectores sociales que nada tienen que ver con su crianza, los comerciantes y los hacendados ${ }^{3}$.

Los dos momentos de la reciente historia altoandina que Bonavia y Flores Ochoa dejan entrever por el predominio y la importancia de la llama o de la alpaca han sido captados también por los habitantes de la microrregión. Muestra de ello es el uso reiterado y consecutivo que hacen de dos expresiones duales del runa simi (idioma del ser humano) ${ }^{4}$ : "llamapaqukuna" ("llama-alpacas") y "paqullamakuna" ("alpaca-llamas"). Para remarcar las diferencias de estas dos expresiones, los habitantes de la microrregión precisan que la primera expresión fue utilizada por las generaciones anteriores y la segunda es utilizada por ellos mismos, en la actualidad. El orden en el que aparecen las palabras "llama" o "alpaca" indica la mayor o menor importancia de la especie animal que aluden. En la primera expresión, por estar mencionada en primer lugar, la mayor importancia corresponde a la llama; y, en la segunda, por la misma razón, a la alpaca. La llama y la alpaca comparten, hoy como antes, la misma expresión, con uno u otro orden, como comparten la misma crianza, pero no la misma importancia.

En la segunda mitad de los años $90^{5}$, la población de camélidos sudamericanos del espacio altoandino del distrito de Vinchos, la parte más extensa y más importante de la microrregión, estaba conformada, como en la actualidad, en su gran mayoría por alpacas, pero éstas eran casi todas híbridas (kuyrukuna, plural de kuyru, híbrido), a consecuencia del cruce con el pequeño segmento de llamas. La semejanza que las alpacas tenían con las llamas era notoria, por sus rasgos físicos y por el grosor de su fibra. Por híbridas, las alpacas eran criadas, más que por la fibra, por la carne.

Por entonces, los criadores de la microrregión preferían utilizar la palabra "llama" para identificar tanto a la Lama glama (llama) como a la Lama pacos (alpaca). La palabra "llama" posponía incluso la expresión "paqullamakuna" (“alpacas y llamas"), que, dada la época e incluyendo a las dos especies, ya les correspondía, y con un orden indicando la mayor importancia de las alpacas. La preferencia de la palabra "llama" obedecía: primero,

1 El estudio del que se desgaja esta ponencia tiene como ámbito esta microregión, ubicada en la más alta de las regiones naturales habitadas que tiene el Perú, entre 3500/4000 y $4800 \mathrm{msnm}$. El nombre que se le atribuye, Occollo, es el de su Centro Poblado Menor más extenso e importante. Se encuentra en la parte superior de la cuenca del río Cachi, entre dos provincias del departamento de Ayacucho, Huamanga y Cangallo, y dos distritos, Vinchos y Chuschi, respectivamente. Comprende 9 comunidades campesinas y 28 localidades. Por tener que ser muy frecuente la referencia a este espacio geoeconómico, en adelante, y para referirse a él, sólo se utilizará la palabra “microrregión” (en cursivas).

2 1996: 69.

3 1990:87.

4 Llamado externamente "quechua".

5 Período en que incursionan las ONG en la microrregión. 
a la costumbre que habían adquirido sus criadores de identificar a la alpaca con el nombre de aquella con la que siempre comparte la crianza y que traía del pasado una casi indiscutible importancia, la llama; segundo, a la suplantación de la población de alpacas puras por la de las alpacas híbridas; y, tercero, a la preponderancia de la llama en el hibridaje de la alpaca.

No es que a los habitantes de la microrregión les haya faltado en ese período un nombre propio, y en runa simi, para identificar a las alpacas que criaban, ni que teniendo ese nombre hayan tendido a olvidarlo por momentos. Desde tiempos inmemoriales, y en runa simi, el nombre propio de la alpaca es paqu. Lo que sucedía con este nombre, como sucede en cierto modo hoy, es su doble posposición: primero, por las expresiones paqullamakuna (hoy) y llamapaqukuna (antes) y, segundo, por la palabra "llama". El uso del término "alpaca", en vez de paqu, es reciente. Empezó a generalizarse desde el momento en que las ONG y dependencias del Estado decidieron involucrar a las unidades domésticas de la microrregión en sus proyectos de desarrollo, y a través de líneas de acción directamente encaminadas a la crianza de la especie animal connotada en el término, para mejorarla genéticamente y mejorar la calidad de su fibra, el producto de mayor valor comercial.

Entre la alpaca y la llama, ha cambiado la importancia que cada cual tiene en el contexto de la ganadería microrregional y la forma de expresarlas, pero no su crianza; ésta sigue siendo compartida. Alpacas y llamas anochecen y amanecen en el mismo corral o dormidero (kancha); empadran y tienen un híbrido (kuyru) por uno y otro lado; comparten el mismo pastoreo, aunque por momentos tengan un desplazamiento distinto, hacia el cerro (urqu) las llamas y hacia el llano y el bofedal (lliwapampa) las alpacas; participan de la misma "herranza", aunque parcialmente las llamas, porque sólo se da acceso a las hembras". En general, alpacas y llamas comparten la misma crianza, las alpacas con un mayor afecto y apego por parte de las mujeres (warmikuna) y las llamas con un mayor afecto y apego por parte de los varones (qarikuna).

En su concepción y en la continuidad de su práctica cotidiana, la crianza de camélidos sudamericanos de la microrregión es una actividad humana que pone en interacción los siguientes componentes básicos: las alpacas y las llamas (paqullamakuna), como animales objeto de crianza $(\text { uywakuna })^{8}$; las divinidades $\left(\right.$ Apukuna $\left.{ }^{9}\right)$, como propietarias de las paqullamakuna; los hombres ${ }^{10}$ de puna (puneños) u hombres del piso ecológico sallqa (sallqa runakuna), como criadores (uywaqkuna) de las paqullamakuna en este mundo (Pachamana), y procurando que la relación uywakuna (sin “q”) - uywaqkuna (con “q") sea siempre una "crianza mutua"; y, finalmente, la estancia (hatus), como centro de crianza o escenario central. Estos cuatro componentes básicos, al interaccionar, adquieren muchas y variadas expresiones. Las que se presentan a continuación, y ordenadas en diez rubros, son las que con más cercanía y continuidad aparecen en la comprensión del valor social y cultural que tiene la crianza de camélidos sudamericanos en la reproducción de las unidades sociales de la microrregión; y, del mismo modo, en la confrontación de los conocimientos que de ella se desprenden con aquellos que ofrecen los trabajos de investigación más

6 Fiesta que cada unidad doméstica realiza para señalarlas y marcarlas, con una alta dosis de ritualidad.

7 Las llamas macho tienen su propia "herranza", que es la fiesta del llamatumachiy (hacer tomar a la llama), que en lo principal consiste en suministrarles un brebaje para efectos sanitarios, después del viaje que realizan a la qichwa (piso ecológico intermedio), a medio año y para el intercambio de productos.

8 Viene de uywa, que en castellano significa crianza. Uywakuna, entonces, y traducido al castellano, significa animal criado, animal de crianza o animal doméstico.

9 Que en su traducción al castellano son las divinidades masculinas, es decir, "los Dioses o Grandes Señores que todo tienen y todo pueden".

10 Como seres humanos, incluyendo tanto varones (qarikuna) como mujeres (warmikuna). 
recientes sobre el pastoreo altoandino llevados a cabo en otras demarcaciones territoriales del país.

\section{Criadores entre unidades familiares y unidades sociales}

En la microrregión, la crianza de camélidos sudamericanos no tiene otro patrón de explotación que no sea el individual; está, en consecuencia, al margen de formas de organización colectiva como las que existen en el sur y el centro del país (por citar, cooperativas, SAIS y empresas comunales). Vistas con una proyección concéntrica, las unidades sociales que la hacen posible son varias y sucesivas; pero, hay una de la que más depende su continuidad y seguridad, además de ser la que casi con exclusividad capta los beneficios, su proceso y sus resultados: la unidad doméstica.

Entre los estudios sobre la economía altoandina realizados en el país son muy pocos los que dan cuenta del significado y la trascendencia que tiene la unidad doméstica en el proceso de la crianza de camélidos sudamericanos. Lo que caracteriza a la gran mayoría de esos estudios es dejar, en el proceso a ser seguido, prácticamente inadvertida a las instancias de decisión y organización social que le sirve de punto de partida, al usar uno $\mathrm{u}$ otro de estos dos procedimientos: transferir las atribuciones de la familia extensa a la familia nuclear o a la familia extensa, de manera precisa y directa; o, cuando no logran sobreponerse a las incongruencias que este procedimiento ocasiona, transferir los mismos atributos a ambas formas de parentesco, de manera ambigua e indirecta, como esperando que sea la ambigüedad la que diluya todo aquello que aparezca discordante. Lo que en el fondo hacen con una $u$ otra transferencia es sobrevalorar las manifestaciones que tiene la crianza de camélidos sudamericanos en la esfera familiar, y a costa de aquellas que, a la vez y necesariamente, tiene en la esfera social.

Significa, entonces, que no se tiene todavía un conocimiento adecuado de lo que, en lo fundamental, es la crianza de camélidos sudamericanos en el área andina, porque, de no ser así, ya se sabría que en el proceso que tiene que seguir, por la confluencia de sus demandas internas y externas, es insuficiente lo que le brinda la esfera familiar, y que, por tanto, sus manifestaciones no son todo lo que se tiene que tomar en cuenta para captar con un sentido de totalidad las fuerzas que la impulsan, los propósitos que persigue y los intereses que pone en juego. Además, ya se sabría que privilegiar la esfera familiar a costa de la esfera social trae consigo una serie de imprecisiones y equivocaciones respecto al esclarecimiento de su racionalidad. Se sabría que cuando los atributos de la unidad doméstica son transferidos al dominio de la familia nuclear, lo que resalta es la no demarcación de las fronteras y la no identificación de las pertenencias; cuando la transferencia de los mismos atributos es al dominio de la familia extensa aparece como que todo en ella se redujera a la capacidad de cooperar y complementar, dejando de lado la capacidad de decidir y ejecutar; y, cuando la transferencia es a uno $\mathrm{u}$ otro de los dos anteriores dominios, indistinta y ambiguamente, no hay cómo dar cuenta de su unidad y proceso.

Dentro o fuera de la microrregión, la crianza de los camélidos sudamericanos opera entre el contexto familiar y el contexto social, y como medio y fin de la articulación de ambos. Las indecisiones, que con frecuencia se presentan cuando se trata de determinar a cuál de los dos contextos es que corresponde su conducción ("manejo", según la tecnología convencional), se originan cuando no se repara que se tiene al frente una actividad humana que demanda agrupamiento, organización y toma de decisiones de interés común, y no se tiene la inquietud de saber dónde y de qué modo se atienden estas demandas. No todas las instancias de organización y decisión que compromete la crianza de camélidos 
sudamericanos, y menos ahora que es predominantemente de alpacas, pueden ser ubicadas en el mismo contexto. Las familias nuclear y extensa son instancias de organización y decisión del contexto familiar y son de naturaleza distinta comparadas con las del contexto social. A diferencia de las familias nuclear y extensa, y respecto a ambas, la unidad doméstica tiene una ubicación intermedia, pero, a pesar de las ambivalencias que conlleva esta su ubicación, es a sus manifestaciones sociales que se debe el carácter central que tiene en el conjunto de la formación social altoandina.

En la lógica de su funcionamiento, la unidad doméstica abarca en una primera instancia los espacios del contexto (de la esfera) familiar. Luego, cuando ese contexto no satisface sus requerimientos, la transpone e ingresa en el otro contexto, en el social, en el que las relaciones ya no encuentran trascendencia en el parentesco, sino en otros aspectos que se justifican socialmente. Por los primeros espacios que cubre es que se tiende, y con mucha frecuencia, a constreñirla en el contexto familiar, cuando, en realidad, lo que prevalece en él es el de servir de puente entre los contextos familiar y social.

La unidad doméstica no es una familia nuclear (taksa ayllu), como tampoco, y mucho menos, una familia extensa (hatun ayllu). Puede, eso sí, coincidir con la familia nuclear pero bajo esta condición: que el grupo humano implicado, al ser puesto en perspectiva económica, se mantenga como tal, $\mathrm{o}$, dicho en otros términos, que en la unidad de ese grupo humano ya no prevalezcan las relaciones de parentesco, sino las relaciones económicas. Cuando la unidad doméstica coincide con la familia nuclear no significa que haya encontrado justificación en razones imputables a su naturaleza, sino en la necesidad y la posibilidad de mantener su unidad en un contexto en el que las relaciones de parentesco ceden su primacía a las relaciones económicas. Puede la unidad doméstica funcionar en el marco de la familia extensa, aglutinando una o más de sus familias nucleares, pero, al darse el caso, son las relaciones económicas las que definen la lógica que sigue, mientras las relaciones familiares se encargan de ofrecer las condiciones para que esa lógica pueda ser expresada realmente.

\section{¿Cuándo los criadores conforman unidades domésticas?}

La posibilidad de que las familias nucleares puedan ser a la vez unidades de producción existe en la microrregión, como en toda el área andina. Una afirmación semejante no se puede ser hecha en el caso de las familias extensas. La idea de que las familias extensas sirvan de soporte a unidades de producción colectivas puede en algún momento de exacerbado optimismo, inquietar la mente de algunos agentes externos del desarrollo rural, pero la posibilidad de ponerla en práctica es simplemente impensable, por lo menos hasta ahora. A diferencia de la familia extensa, la familia nuclear sí puede, como productora de bienes económicos y en determinadas condiciones, llegar a ser una unidad de producción. Pese a que hay consenso en la admisión de esta su importancia, muy pocos aciertan en señalar las razones por las que llega a tenerla y las circunstancias que la hacen posible. Las dudas aparecen cuando se comprueba que no todas las familias nucleares son unidades de producción, y se agudiza cuando en esta comprobación se llega a conocer que hay familias nucleares que no pueden llegar a alcanzar tal condición y otras, en cambio, las pierden.

¿Cuándo una familia nuclear llega a ser o deja de ser unidad de producción? Cuando, como parte de ese ciclo de "soledad, pobreza, dependencia, domesticación, autonomía, riqueza económica y social, y reversión de los términos" ${ }^{11}$, considerado un ideal andino,

11 Ortiz, 1,989: 147. 
llega a ser y deja de ser una unidad doméstica. Relacionar la unidad doméstica al ideal humano identificado por Alejandro Ortiz, significa admitir su carácter cíclico y transitorio. Decir que "un buen anciano ha de ser pobre; un buen adulto, acomodado y sociable; un joven deber ser 'altivo y rebelde,", y que "alejarse de este modelo es sentido como una desgracia: un anciano rico es un avaro; un adulto pobre, ocioso y pecador; un muchacho demasiado sumiso, será un débil sin futuro" 12 , es reconocer que no siempre la familia nuclear es unidad de producción, aunque pueda ser siempre unidad de consumo; esto, en última instancia, quiere decir que no siempre es unidad doméstica. La unidad doméstica se define por la interrelación entre producción y consumo y por la convergencia, en pequeña escala, de las tendencias individuales y colectivas de sus miembros ${ }^{13}$.

En la actualidad, las posibilidades de desarrollo de la crianza de camélidos sudamericanos serían prácticamente inexistentes si sólo dependieran del aporte de la familia nuclear altoandina, por lo insuficiente que es casi siempre la capacidad laboral del conjunto de sus miembros; por muchos que puedan ser éstos, no son en su mayoría permanentes. Además, los rigores que le impone el medio ambiente contribuyen también a que esta insolvencia laboral de la familia nuclear sea constante y casi natural. No hay, en la actualidad, una familia nuclear donde: primero, las exigencias laborales no excedan, casi siempre, a las que en respuesta pueden ofrecer sus miembros; segundo, la capacidad laboral que aguardan sus miembros tenga que ser necesariamente complementada con la de los otros miembros de su familia extensa o de su vecindad; y, tercero, haya la necesidad de ser a la vez unidad doméstica, dado que sólo unificando potencialidades individuales y colectivas internas se puede dejar sentir el peso específico de su autonomía económica, dando por deber y obligación y recibiendo por derecho. Es en virtud del derecho ganado en el cumplimiento de los deberes y las obligaciones que la familia nuclear extrae de la familia extensa la fuerza laboral que le hace falta.

Una unidad doméstica no sustituye ni a la familia nuclear ni a la familia extensa, ni mucho menos; lo que hace es aunar y complementar las capacidades y potencialidades que tienen ambas frente a sus carencias. Son muy pocas las unidades domésticas conformadas por una sola familia nuclear; la conformación mayoritaria es la de dos o tres familiares nucleares, de dos o tres generaciones. En la unidad doméstica se comparte la residencia, la comida y las actividades económicas, y en la crianza de alpacas, el manejo de los animales por rebaños, bajo el reconocimiento de que los hatos que conforman estos rebaños son de propiedad de cada familia nuclear.

\section{No todas las unidades domésticas crían alpacas y llamas}

No todas las unidades domésticas de la microrregión son criadoras de camélidos sudamericanos, que en sus condiciones se reduce a las alpacas y llamas. El volumen de unidades domésticas con crianza de alpacas y llamas de cada localidad guarda relación con la ubicación vertical que le corresponde. Las localidades que se encuentran a mayor altura tienen un volumen mayor y las que se encuentran a menor altura, un volumen menor. Para tener alguna mayor idea de lo que esta gruesa cuantificación implica es necesario no dejar de considerar que la crianza de camélidos sudamericanos de la microrregión está restringida a la de alpacas y llamas, con un casi absoluto predominio de las primeras, como también diferenciar sus localidades por la altura, a sabiendas que todas son altoandinas: los de mayor altura, los de mediana altura y los de menor altura.

12 Ortiz, 1,989: 147.

13 Ossio y Medina: 1,985: 89. 
Todas las unidades domésticas de las localidades de mayor y mediana altura son alpaqueras; pero, en las localidades de mayor altura hay un pequeño grupo de familias, en el orden del 4 ó 5\% aproximadamente, que no son propietarias de las alpacas que crían, y que si son consideradas "alpaqueras" es porque ejercen la actividad para otros, a cambio de lo que les corresponderá del incremento anual de animales que crían, y con eventuales pagos en productos alimenticios ${ }^{14}$. En este pequeño grupo de unidades domésticas se encuentran las que están a cargo de las viudas y mujeres abandonadas, más conocidas como "warmisapakuna", un término runa simi que traducido al castellano es "abundante en mujeres". Las unidades sociales a cargo de las warmisapakuna carecen de varones con capacidad laboral plena, por lo que la economía que les da soporte depende fundamentalmente de lo que pueden aportar las mujeres. En las localidades de mediana altura, siendo todas alpaqueras, no existen unidades domésticas que estén a cargo de las warmisapakuna, debido a que, cuando aparecen y llegan a no tener animales, sus miembros tienden a establecerse en las localidades vecinas, ubicadas en el piso ecológico suni o qichwa, en las que tienen acceso a tierras de cultivo. Y, finalmente, en cuanto a las localidades de baja altura, cabe indicar que lo que más las caracteriza es la existencia de un considerable sector de unidades domésticas que no se dedican a la crianza de alpacas, estimada aproximadamente en un $48 \%$, casi una mitad. Esta característica se debe a que controlan territorios que se encuentra en la zona ecológica suni, con ventajas para la actividad agrícola y para la crianza de vacunos y ovinos. Para los integrantes de sus unidades domésticas, la crianza de camélidos sudamericanos es una actividad a la que no pueden llegar por más grande que sea la carencia económica que puedan tener, simplemente porque no les corresponde; y, por la superior identidad social que con este punto de vista asumen, hay en ellos un cierto menosprecio por aquellos que la llevan a cabo.

\section{Rebaño y otros conceptos afines entre los criadores}

Por la complejidad de las relaciones sociales y técnicas que se dan alrededor de la crianza de alpacas y llamas, se hace necesario hacer una confrontación de los términos "ganado", "rebaño" y "hato", tomando como base los criterios que adoptan los habitantes de la microrregión para configurar los agrupamientos de los animales que crían y las diferencias que entre ellos establecen. Los tres términos son usados profusamente en el campo de la promoción del desarrollo agropecuario, pero sus agentes los toman como si fueran sinónimos, indistintamente y sin jerarquizarlos.

Cuando los habitantes de la microrregión tienen que referirse a los animales que crían, lo hacen presentándolos en tres agrupamientos básicos, y sin darle un nombre específico a cada cual en runa simi. Los tres agrupamientos se diferencian por el tamaño, la jerarquía y los rasgos de discriminación, y, para efectos de esta discriminación, cada agrupamiento está implicado de manera sucesiva en el otro. Aunque no haya un nombre específico en runa simi para cada uno, los tres agrupamientos, al ser confrontados con los manejados por los agentes externos de la promoción social, y expresados muy débil y tenuemente en los términos "ganado", "rebaño" y "hato", dan pie a que se pueda hacer una especie de "concordancia semántica transcultural", como la que se muestra en el siguiente cuadro:

14 Martínez Alier dio cuenta, hace 36 años, y en el centro del Perú, de una variante de pastores de ovejas que se asemeja a este reducido grupo de alpaqueros, a los que llamaban "huacchilleros" (1973: 64), como, seguramente, siguen llamándolos todavía así en la actualidad. 
USO "TRANSCULTURAL"

DE LOS TÉRMINOS “GANADO”, "REBAÑO” Y "HATO”

\begin{tabular}{|c|c|c|c|c|}
\hline \multicolumn{2}{|c|}{ Implicancia } & \multicolumn{3}{|c|}{ Término (palabra) } \\
\hline $\begin{array}{c}\text { General } \\
\text { (semejanza) }\end{array}$ & $\begin{array}{l}\text { Específica } \\
\text { (diferencia) }\end{array}$ & "Ganado" & "Rebaño" & "Hato" \\
\hline Agrupamiento (animal) & & $\mathrm{X}$ & $\mathrm{X}$ & $\mathrm{X}$ \\
\hline Conducción (humana) & & $\mathrm{X}$ & $\mathrm{X}$ & $\mathrm{X}$ \\
\hline & $\begin{array}{l}\text { Tamaño (relativamente) } \\
\text { mayor del agrupamiento }\end{array}$ & $\mathrm{X}$ & & \\
\hline & $\begin{array}{l}\text { Tamaño (relativamente) } \\
\text { mediano del agrupamiento }\end{array}$ & & $\mathrm{X}$ & \\
\hline & $\begin{array}{l}\text { Tamaño (relativamente) } \\
\text { pequeño del agrupamiento }\end{array}$ & & & $\mathrm{X}$ \\
\hline & $\begin{array}{l}\text { Ningún tipo de } \\
\text { discriminación }\end{array}$ & $\mathrm{X}$ & & \\
\hline & $\begin{array}{l}\text { Discriminación del } \\
\text { agrupamiento por especie }\end{array}$ & & $\mathrm{X}$ & \\
\hline & $\begin{array}{l}\text { Discriminación del } \\
\text { agrupamiento por propiedad }\end{array}$ & & & $\mathrm{X}$ \\
\hline
\end{tabular}

Lo primero que muestra el cuadro, y como semejanzas, son dos implicancias generales y obvias: primero, que son agrupamientos de animales, y, segundo, que, como tales, requieren de conducción humana, aquella que se les ofrece a través de la unidad doméstica. Luego aparecen, y como diferencias, las implicancias específicas: en primer lugar por el tamaño, del que depende la jerarquía que tienen; y, en segundo lugar, el tipo de discriminación que conllevan, con la salvedad de que el "ganado" es el único agrupamiento animal que no conlleva ningún tipo de discriminación.

De este modo, las diferencias entre los términos (las palabras) "ganado", "rebaño" y "hato" resultan ser: "ganado" no implica en sí discriminación por especies para el pastoreo ni discriminación e identificación para el reconocimiento del derecho de propiedad; "rebaño" implica en sí discriminación por especie para el pastoreo, pero no discriminación e identificación para el reconocimiento del derecho de propiedad; y "hato" no implica en sí discriminación por especie para el pastoreo, pero sí discriminación e identificación para el reconocimiento del derecho de propiedad. En este marco, decir "ganado mixto" resultaría innecesario, tanto por especie como por propietario, porque en ambos casos sí es de hecho; decir "rebaño mixto" sí es necesario por especie, porque no es de hecho, pero no por propiedad, porque sí es de hecho; y, decir "hato mixto" sí es necesario, tanto por especie como por propietario, porque en ambos casos no es de hecho.

Cuando una unidad doméstica está conformada por dos o más familias nucleares y sus miembros dicen que "crían ganados" (así, en plural e internamente), significa que ella tiene tantos grupos de animales como familias nucleares, sin hacer referencia a los rebaños que conforman los animales que crían (conducen o manejan). Los animales de los "ganados" (así en plural) se discriminan entre ellos mismos por especies y, al hacer esto, conforman rebaños. Esta tendencia natural de los animales impone a que la conducción, 
principalmente para el pastoreo, sea por rebaños, es decir por especies. Sólo las alpacas y las llamas comparten parcialmente la conducción, por la gran afinidad que tienen; las demás especies, conformando rebaños, son conducidas autónomamente.

La discriminación de los animales no es sólo por el manejo, es también por el derecho de propiedad que se cierne sobre cada uno de ellos. Es cuando los animales son discriminados por el derecho de propiedad que aparecen los hatos al interior de los rebaños. A los animales que, en un rebaño, conforman un hato en la ceremonia de la herranza se les adscribe o confirma una determinada identificación, expresada en una marca o una señal. Si bien la herranza es por rebaños, no es porque éstos tengan que ser discriminados e identificados que se la realiza. Su razón de ser es discriminar e identificar cada uno de los hatos que lo conforman, y que pertenece en propiedad a cada familia nuclear integrante de la unidad doméstica.

\section{El aporte familiar, desde los niños hasta los ancianos}

La crianza de alpacas y llamas es una actividad humana que en el contexto familiar traspone, con mucha frecuencia y con distintos tipos y grados de demanda y beneficio, el espacio de interacción que hay entre padres e hijos, para ampliarse en el que hay entre los abuelos, bisabuelos, nietos y bisnietos, y, también, el de los hermanos, para ampliarse en el de los tíos y primos, por línea paterna o materna. Casi todos los compromisos generacionales y colaterales que se establecen en el contexto familiar tienden a patentizarse en acciones de cooperación, las que, al ser tanto en servicios como en bienes, encuentran en la reciprocidad la mejor garantía de continuidad.

Entre las actividades humanas, la agricultura es la que impone mayores exigencias laborales a los varones y la ganadería a las mujeres. Entre los criterios que se adoptan alrededor de la división del trabajo, los que más gravitan son los que tienen relación con la crianza de alpacas y llamas, y no hay mayor explicación que pueda estar detrás de esta percepción que el valor que esta actividad humana tiene en la cosmovisión altoandina. Según esta cosmovisión, el mundo (pacha) tiene dos fueros: uno interno y femenino y otro externo y masculino; el primero, por ser de la Pachamama, corresponde a las mujeres y sus compañeras, las alpacas; y, el segundo, por ser del $A p u$, corresponde a los varones y sus compañeros, las llamas. Esta división del mundo, expresado como fueros o dominios, es la base de la división del trabajo. Aunque las alpacas y las llamas son criadas como si conformaran un solo rebaño no comparten el mismo fuero o dominio, pero ambas especies animales son adscritas laboralmente a las mujeres, y cuando éstas las asumen, comprometen a los miembros de la familia que más dependen de su cuidado: los menores de edad, varones y mujeres. En un espacio social como la altoandina (sallqa), donde la actividad pecuaria es tanto o más importante que la agrícola, es por la crianza de los animales por lo que las mujeres y los menores de edad logran eximirse de la mayor parte de las actividades de labranza.

El pastoreo, la protección del rebaño durante el día y a campo abierto, y de modo especial el cuidado de las crías, son las actividades alpaqueras que absorben gran parte de la capacidad laboral de las mujeres y de sus aliados, los menores de edad.

El trabajo de los varones con respecto a las alpacas y las llamas es de hecho menos continuado que el de las mujeres, puesto que destinan la mayor parte del tiempo al trabajo agrícola familiar e interfamiliar, a los viajes (para la búsqueda de otras ocupaciones laborales), a la atención de compromisos interfamiliares (que por lo general son trabajos de ayni minka) y al cumplimiento de las faenas y las otras obligaciones impuestas comunal, 
local o barrialmente. No obstante, hay actividades dentro de la crianza de alpacas que corresponden casi exclusivamente a los varones mayores de edad: la esquila y la protección del rebaño en las noches, en los dormideros o corrales (kanchakuna).

En la crianza de alpacas y llamas de la microrregión no existe trabajo a cambio de salario. $\mathrm{Ni}$ en las explotaciones asociativas, comunales y locales, que se ensayan con rebaños de alpacas aparecen las relaciones laborales mediadas por el dinero. En estos intentos de explotación asociativa que realizan las comunidades y las localidades, el rebaño de alpacas es entregado a una, dos o más unidades domésticas, de aquellas que las integran, para que sean éstas las que se encarguen de cuidarlo y pastorearlo, y por una retribución en trabajo agrícola y en animales. La retribución en trabajo agrícola consiste en que la comunidad o localidad tiene que atender, mediante faenas, las labores de sus campos de cultivo; $y$, la retribución en animales, en que una u otras de las mismas unidades sociales tiene que donarles, en cada ciclo anual, un número de animales, determinado como porcentaje de incremento. Si en la última retribución están implicadas dos o más unidades domésticas, y como éstas cumplen el compromiso de cuidar y pastorear el rebaño por turnos, la cantidad de animales es dividida en partes iguales.

El pastoreo es considerado la labor más importante de la crianza de alpacas, y sus exigencias son más en tiempo y cuidado que en despliegue de esfuerzo o desgaste de energía. Cuando la fuerza laboral de la unidad doméstica resulta ser escasa para la labor se recurre a la cooperación, tanto en el contexto familiar como en el vecinal, siendo mucho más frecuente en el primero que en el segundo. En circunstancias de mayor carencia de fuerza de trabajo para el pastoreo es cuando la cooperación, inscrita en la reciprocidad, se manifiesta en niveles recurrentemente más elevados, comparados con los que llega a tener con las otras actividades. Para la cooperación en el pastoreo, las unidades domésticas establecen, según sus exigencias y posibilidades, convenios de trato directo que se cumplen por turnos que no exceden el período semanal. En el cumplimiento de los turnos no se toma en cuenta la cantidad de animales entre las partes; en este sentido, puede darse el siguiente caso real, por ejemplo: un hermano con más de 2 rebaños y con total de 80 animales frente a una hermana con un rebaño de sólo 10 animales.

\section{La extensión del afecto y trato familiar en la crianza}

La llamada "cartera de crianza"15 de las unidades domésticas es amplia en cuanto a especies animales, y sin que ninguna de ellas pueda dejar de depender de los pastos naturales. La "cartera de crianza" de una unidad doméstica es armada, por lo general, por dos o más de estas especies animales o rebaños, enumeradas según el orden de importancia que se les atribuye en la actualidad: alpacas, llamas, ovinos, vacunos, equinos, caprinos y porcinos. Los porcinos no tienen más alimento que los pastos naturales, pero a diferencias de las otras especies animales, causan más perjuicios, pues prefieren lass raíces, al buscarlas, escarban los pastizales, como barbechándolas ${ }^{16}$.

Entre todas las especies animales que se crían en la microrregión, sólo las alpacas y las llamas reciben un trato familiar al interior de las unidades domésticas. Intensas, expresivas y tiernas son las manifestaciones de afecto que sus miembros generan alrededor de ellas, comparables con lo que es natural encontrar entre parientes muy cercanos. Sus canciones adquieren una mayor significación en este sentido al incorporar, para referirlas, las palabras "padre", "madre”, "hermano", "hermana", "hijo", "hija”, "patrón” y "patrona”, y por lo

15 Expresión introducida en la actividad pecuaria por quienes promueven en ella la teoría de sistemas, y para dar cuenta y diferenciar los rebaños conducidos por una unidad doméstica.

16 A este hecho se debe el nombre de "tractorcitos", que jocosamente le dan sus propios criadores. 
general con diminutivos, como para que así no se dude del afecto íntimo que sienten por ellas. No hay unidad doméstica en la que sus miembros dejen de manifestar que no pueden vivir sin sus alpacas y sus llamas; que es mutuo el cuidado que se brindan con ellas; que la mujer se identifica y adquiere mayor compromiso con la alpaca; $y$, que el varón hace lo mismo con las llamas, por compartir la masculinidad y los trabajos más rudos.

Remarcar que la alpaca y la llama han estado en el pasado, están en el presente y estarán en el futuro de la microrregión es algo que sus habitantes cumplen consecuentemente y como el cumplimiento de un compromiso que han adquirido en algún momento de la historia que protagonizan. Los de mayor edad, especialmente los de la tercera edad, al hacer memoria que aprendieron de sus progenitores, evocan con mucho afecto y mucha gratitud las historias que protagonizaron con las llamas y alpacas; y, los de menor edad, especialmente los jóvenes, al describir e interpretar los hechos que en el presente comprometen a sus unidades sociales y la forma cómo a través de ellas los afrontan, lo hacen con el mismo sentimiento. No hay nada que sus habitantes, en conjunto o por generaciones, que no la tomen como referente para dar a entender lo que piensan, sienten y desean.

En el más importante mito de origen de la microrregión, las llama-alpacas llegan a este mundo (kaypacha) como una bendición divina, traídas del mundo interior o mundo de adentro (ukupacha) por una mujer, y a través de una laguna (hatunqucha) que hace de paqarina, lugar por donde, las divinidades, que son del ukupacha, llegan al kaypacha ${ }^{17} \mathrm{y}$ vuelven de ella. Habiendo estado un tiempo en el kay Pacha, las llamapaqukuna retornan al mundo de donde vinieron, el ukupacha. Si la llegada de las llamapaqukuna al kaypacha fue una bendición, el retorno al ukupacha fue una maldición, y en ambos casos por mandato divino. Las llamapaqukuna retornan al ukupacha por la misma paqarina, conducidos por la misma mujer y a consecuencia del maltrato que ésta había recibido por parte de su pareja, un varón del kaypacha, cuando se vio obligada a defender a una de sus llamas. Antes, el varón del kaypacha había sido objeto de una certera patada por parte de la llama, en el momento en que, creyendo que estaba enferma, intentó "curarle" la arqata ${ }^{18}$, un grave error que la llama no perdonó, por ser de alguien con el que más convive y que, por tanto, lo debe conocer mejor. Cuando las paqullamakuna corrían, tras la mujer, hacia el centro de la laguna, buscando el punto preciso para el retorno al ukupacha, el varón del kaypacha y sus dos hermanos lograron enlazar a unas cuantas llamapaqukuna, aunque, al final, los tres quedaron petrificados, mirando de bruces la laguna, como deplorando la maldición que habían ocasionado. De las pocas llamapaqukuna que lograron enlazar desciende la escasa población ganadera que hoy existe en la sallqa (espacio altoandino o puna) del kaypacha.

En una unidad doméstica el grado de relación entre sus integrantes y los camélidos sudamericanos objeto de crianza varía según el sexo y la etapa en el ciclo de vida de los primeros. Fuera de la visión ontológica que vincula a las alpacas con las mujeres y a las llamas con los varones, las relaciones entre los criadores y sus crianzas se patentizan en el pastoreo, que en lo sustancial implica cuidado, tiene variadas manifestaciones. En el caso de las alpacas (paqukuna), tales relaciones son íntimas con las mujeres, los niños (y las niñas) y los ancianos (y las ancianas), y alejadas con los jóvenes y los adultos, y más cuando son del sexo masculino. Los jóvenes y adultos varones se alejan de las alpacas, antes que por una mayor dedicación a la actividad agrícola, por lo frecuente que son sus viajes y abandonos cuando migran.

17 Por este lugar de tránsito es que a las divinidades se las considera paqariq, el que aparece y desaparece. El lugar, así como es una laguna, puede ser también un manantial (pukyu).

18 Una especie de lunar, ovoidal y de regular tamaño, que las alpacas tienen en cada brazos y pierna. Se dice que es la marca de sus propietarios, las divinidades, siendo sus criadores, apenas, sus prestatarios. 
El grado de familiaridad que hay entre las mujeres y las alpacas (paqukuna) es tan íntima que cuando a una de las criadoras de mayor edad se le preguntó cómo hacía para identificar a sus animales siendo tantas, respondió como ante una impertinencia: “¿cómo una madre no va a poder reconocer a sus hijos e hijas?". En el mayor afecto hacia las alpacas, las mujeres están acompañadas por las niñas y los niños, para quienes las alpacas tiernas (uña paqukuna) son sus hermanitos; les ponen nombres, juegan con ellas, las protegen, lloran cuando se enferman.

Los ancianos (yuyaq) varones dan a conocer con mucho orgullo que con las llamas llegaron a tener las mejores experiencias de sus vidas, y cuando las recuerdan la hacen entre canciones, como la que se presenta a continuación ${ }^{19}$, captada en Cayramayo ${ }^{20}$ :

Vamos wauqichay, ;carajo!,

Ima punchautam lluqsiykusunchik.

Vamos, wauqichay, puririkusun.

Vamos, hermanuy, purikusun.

Lunesninpichu, martesninpichu, sabadunpichu.

Kinsa diachalla.

Diachallanchik, qarikunalla.

Vamos, hermano, puririkusun.

Ichuqchanmanchu, alliqchanmanchu.

Suchiriy, asnero, nuqaraq pasasaq.

Suchuriy, mulero, ñuqaraq pasasaq

Karun purinay, anchan jornaday.

Karun purinay, anchan jornaday.
Vamos, hermanito, ;carajo!

Qué día vamos a salir

Vamos, hermanito, caminaremos.

Vamos, mi hermano, caminemos.

¿Un lunes?, ¿un martes?

¿Un sábado?

Tres diitas nada más.

Es nuestro diita, oh varones.

Vamos hermano, caminemos.

¿A la izquierdita? ¿A la derechita?

Ponte al lado, asnero, yo tengo que pasar primero.

Ponte al lado, mulero, yo tengo que pasar primero.

Es lejos lo que tengo por caminar, grande es mi jornada.

Es lejos lo que tengo por caminar, mucho es mi jornada.

Por el gran afecto que sienten por las alpacas y las llamas y como una respetuosa y agradecida manifestación del valor que tienen en el mantenimiento de sus unidades domésticas, los habitantes de la microrregión las ven incorporadas en el círculo familiar. Cuando son de mayor edad, les llaman, como a sus progenitores, "mama" ("madre") y "tayta" ("padre"), respectivamente; y, cuando son de mediana y menor edad pueden ser "wawqi" ("hermano") o "pani" ("hermana") para los varones y "turi" ("hermano") o "ñaña" ("hermana") para las mujeres, o también "churi" (hijo) para los varones y "wawa" (hija) para las mujeres. La canción que antecede, por ejemplo, cantada por los varones, es alusiva a la llama, a la que mencionan como "mi hermanito" ("wauqichay").

Una parte considerable de lo que consumen en la alimentación, al no poder ser producidas internamente, es conseguida gracias a los camélidos sudamericanos, y mediante el qichwariy ${ }^{21}$, adquiere en los habitantes de la microrregión una alta valoración. Mucho valoran también el que gracias a las alpacas y llamas puedan consumir carne, fresca o

19 Que también aparece en un trabajo de investigación presentado por Ubilluz para la obtención del bachillerato, 2003: 24.

20 Una de las localidades altoandinas de la comunidad de Paccha, distrito de Vinchos.

21 Viaje que los habitantes de la microrregión realizan cada año, con una recua de llamas, a lugares ubicados en el piso ecológico qichwa, con el propósito de adquirir, mediante el trueque (intercambio no monetario), maíz, trigo y otros productos no producidos internamente. 
deshidratada y seca (charki); contar con pieles que los protegen de la humedad mientras duermen; disponer de "lana" (fibra) para la confección de las prendas que lucen en los días memorables; conseguir las mejores ofrendas para las divinidades; $y$, encontrar en ellas mismas el bien que más los enaltece y les llena de orgullo. Para sus criadores, estas ventajas, de las que ellos más directamente aprovechan, significan tanto o más que aquellas que se materializan con la mediación del dinero.

\section{Las mujeres con las alpacas y los varones con las llamas}

En la segunda mitad de la década de los años 90, como ya se ha informado, en las localidades altoandinas del distrito de Vinchos se prefería utilizar la palabra "llama" para identificar tanto a la especie animal a la que realmente corresponde, la llama, como a la que no le corresponde, sino por afinidad, la alpaca. Hoy, transcurridos casi tres lustros, la palabra "alpaca" está generalizándose como una identificación totalmente diferenciada de la palabra "llama", aunque combinándola todavía en el uso con la expresión "alpaca-llama" ("paqullamakuna"), que identifica a las dos únicas especies de camélidos sudamericanos que se crían en ámbito distrital, como en la microrregión, y en orden de importancia.

Por el artículo que se utiliza para nombrar tanto a la alpaca como a la llama, correspondería atribuir a ambas especies de camélidos sudamericanos una connotación femenina, pero no es así como aparecen en el pensamiento de sus criadores. Para éstos, la connotación femenina sólo corresponde a la alpaca, y por su mayor ligazón con la criadora, la mujer; la llama, en cambio, tiene una connotación masculina, por su mayor ligazón con el criador, el varón. Pero, a pesar de que se hace esta diferencia, ese mismo pensamiento mantiene todavía la tendencia a favorecer lo masculino frente a lo femenino, la condición de varón frente a la condición de mujer y la valoración de la llama frente a la valoración de la alpaca. Otra de las razones de por qué que sus criadores no hacen una tajante distinción entre la alpaca y la llama -como en el caso de preferir llamar a ambas con los términos de "llamapaqukuna" ("llamas y alpacas"), antes, y "paqullamakuna” (“alpacas y llamas”), hoy- parece estar también en la mantención de esta tendencia.

Una importante muestra de cómo los criadores privilegian lo masculino frente a lo femenino es el pagapu (pago u ofrenda al Apu, Dios o Gran Señor) que se realiza en el proceso de la "herranza" de alpacas. En esa ceremonia, la alpaca comparte el carácter masculino de la llama, aunque de esta especie animal sólo participan las hembras, y subsidiariamente ${ }^{22}$. El pagapu de la "herranza" de alpacas se lleva a cabo en la parte más elevada y notoria de un cerro (urqu, que además significa macho), es decir en el espacio que corresponde a la llama, dada su masculinidad. Por su connotación femenina le debería corresponder las partes bajas, entre falderías y altiplanicies, y más precisamente en sus hondonadas y oquedades; sin embargo, no son estos lugares donde se encuentran sus "paganas", sino en los de las llamas. Las partes bajas y profundas están destinadas para los ovinos y los vacunos, ambas exóticas.

Los ancianos cuentan que en la microrregión existe un tipo de llama al que le adscriben cualidades y atributos especiales, y se refieren a ella con la expresión runa simi “wakasllama”, que al parecer equivale a "wakasllamakuna” (plural de wakallama), que en castellano puede ser traducido como "llamas sagradas"23. A estas mismas llamas, los otros

22 Porque las llamas-macho (urqu-llamakuna) tienen otra "herranza" que es el llamatumachiy (hacer tomar a la llama, una fiesta familiar en homenaje a las llamas-macho que hacen el qichwariy).

23 Aunque el uso de la palabra "waka" ("huaca") como lo sagrado (Rostworowski, 1988: 9) ya no aparezca con la fuerza con que lo hacen las demás palabras del vocabulario runa simi que forma parte de la cotidianidad de la microrregión. 
segmentos de la población microrregional los identifican como urgu llamakuna (llamas de los cerros o llamas masculinas). Ancianos o no, todos las caracterizan como robustas, con tamaño y peso mayores que el promedio. Son las que permanecen principalmente en las partes más elevadas de los cerros, casi sin contacto humano y son las que se prefiere para los qichwariy, especialmente para los prolongados, por la mayor capacidad de carga y resistencia que se les atribuye.

\section{Las diferencias entre llamas $y$ alpacas $y$ sus propias diferencias}

Entre sus criadores, no hay, obviamente, confusión en la identificación de las alpacas y las llamas, pero sí persiste todavía, y en cierto modo, la tendencia a usar para ambas una sola expresión: la de "paqullamakuna" ("alpacas y llamas"), en la que la primera mención corresponde a la alpaca, por su preponderancia e importancia en la actualidad. Ya pocos persisten en usar la expresión anterior, la de "paqullamakuna" ("llamas y alpacas"), en la que la primera mención corresponde a la llama ("llamapaqukuna"), por la misma razón, pero en el pasado; y, ya son pocos también los que se refieren a la alpaca con la palabra "llama", por lo que esta especie de los camélidos sudamericanos significó en el pasado y por compartir con ella la crianza.

Para el criador, la alpaca y la llama merecen el mismo afecto, aunque no sea igual la importancia que a cada una le concede, principalmente por lo que aportan para el mantenimiento de la unidad doméstica. El tamaño de los rebaños que conforman es la muestra más evidente del diferenciado valor que les concede: el de las llamas tiende a ser cada vez más pequeño y el de las alpacas, a ser cada vez más grande. En la actualidad, el ingreso económico que se obtiene por las alpacas es comparativamente mucho mayor que el que se obtiene por las llamas. Los criadores señalan que en el pasado la situación era otra, o iba en sentido contrario, en tanto era la llama la que más contribuía al mantenimiento de las unidades domésticas, indicando que el tamaño de los rebaños que conformaban era prueba de ello, mucho más grande que los actuales.

La denominada "cartera de crianza" de las unidades domésticas de la microrregión no sólo es de alpacas y llamas. Incorpora, además, y con un carácter general, a los ovinos, y hay sectores de unidades domésticas en los que dicha "cartera" es ampliada con los vacunos, equinos, porcinos y aves. La crianza de ovinos es de alcance general, aunque el volumen de sus rebaños sea menores que los de las alpacas. Los agentes externos de la promoción del desarrollo altoandino señalan que, en comparación con los ovinos, los camélidos sudamericanos digieren con un $22 \%$ más de eficiencia los pastos naturales que consumen. A pesar de esta opinión técnica en contra y de muchas otras que se esgrimen al compararlos con los camélidos sudamericanos, los ovinos constituyen hoy la fuente de ingreso económico al que con mayor facilidad y frecuencia recurren las unidades domésticas de la microrregión. Sus dos pariciones al año, su demanda permanente y su fácil venta hacen que sus propios criadores los comparen con un banco $^{24}$.

La llama y la alpaca, como todos los camélidos sudamericanos, se asemejan en la estructura biológica pero difieren, entre otros aspectos, en el tamaño, el peso vivo, las razas y en el servicio que brindan a sus criadores. Llamas y alpacas comparten un conjunto de términos comunes para la descripción de sus características biológicas, como por ejemplo, en relación con el sexo: urqu, cuando es macho; china, cuando es hembra; y, maqlla,

24 Para sus criadores, los ovinos constituyen un "banco", pues los venden cada vez que les urge contar con dinero. . 
cuando es hermafrodita. Sin embargo, más allá de este tipo de rasgos comunes, existen muchos otros por los que se particularizan. La cabeza, las orejas, el hocico y el cuello más largo, la cola semirrecta y el ser menos tímida y más altiva son los rasgos que más distinguen a la llama de la alpaca.

Se resalta en la llama, frente a la alpaca, estas cuatro ventajas: resistencia ante las contingencias, tamaño, peso y capacidad de carga. La llama aventaja a la alpaca en el consumo de agua y alimentos, resistencia a los climas más adversos y a las enfermedades y su capacidad de adaptación a distintos ambientes, de preferencia a los lugares secos. Es un animal que puede vivir en todos los pisos ecológicos, por lo que se la considera cosmopolita; no sólo pasta, también ramonea; consume pasto en sitios aparentemente estériles; $y$, tiene la capacidad de convertir la vegetación seca y de alto contenido de celulosa en carbohidratos ${ }^{25}$. Durante el pastoreo, las llamas se apartan entre 4 a $5 \mathrm{~km}$ del punto de emplazamiento; los machos suelen separarse de las hembras y tienen la propensión de irse hacia los cerros más elevados.

El tamaño y el peso son otras dos ventajas que tiene la llama frente a la alpaca. La llama es más grande que la alpaca. La altura de la llama adulta, del piso al crucero, varía entre 1 y 1,20 m, y la de la alpaca, entre 0,60 y $0,90 \mathrm{~m}$. El peso vivo tanto de la llama como de la alpaca varía según el sexo y la raza; el de la llama entre 60 y $150 \mathrm{~kg}$, no siendo significativa la diferencia entre el macho y la hembra. Entre las alpacas, el peso del macho es de $64 \mathrm{~kg}$ y el de la hembra, $62^{26}$.

A diferencia de la alpaca, la llama sigue siendo criada para el servicio de transporte de carga, aunque las rutas que antes se cubrían con sus caravanas hayan sido reducidas a los tramos más próximos, por la construcción de carreteras y el uso de vehículos a combustible. Además, en la disminución del volumen de la crianza de llamas cuenta también la preferencia de las últimas generaciones por los equinos, como medios de transporte, en perjuicio de las llamas. Si la crianza de la llama se justifica por su capacidad de carga y transporte, la de la alpaca se justifica más por ser productora de carne y fibra, un doble propósito que obedece a que es preponderantemente híbrida.

Además del servicio de transporte que ofrece, la llama vale, como la alpaca, por la carne, la piel y la fibra. La carne de llama se consume en estado fresco y como charki (carne desgrasada, salada y secada). Con la piel de llama se confeccionan productos artesanales resistentes y duraderos, como los zurriagos (chuqikuna) y sandalias (siqukuna). La fibra, por ser gruesa y quebradiza, es utilizada para la elaboración de tejidos gruesos y fuertes, principalmente costales; también para el trenzado de sogas.

Aunque ya expuesta a la demanda del mercado, la alpaca era criada hasta la primera mitad de los años 90 sin una preferencia por la fibra entre sus productos; el valor concedido a la carne era tanto o más que el que tenía este producto. Es recién, en los casi 20 últimos años, y por una persistente influencia de los organismos encargados de promover el desarrollo, que la crianza de alpacas tiende a encontrar mejoras en la producción de fibra, aunque las condiciones no son realmente favorables para esta innovación, ante todo por la precariedad de los recursos. Por la escasa dotación de pastos de bofedal, de las que dependen mayormente las alpacas, las unidades domésticas no pueden dejar de ser (del todo) tolerantes frente al hibridaje de sus animales. Como consecuencia de la hibridación, la fibra de alpaca es de baja calidad, por gruesa y pequeña. En las condiciones actuales, y no obstante la intensificación de las campañas en contra de la hibridación, la continuidad de la crianza de alpacas se debe, más que a la fibra, a la carne. Como posibilidades de

25 Flores Ochoa: 1988: 95.

26 Julio Súmar, por referencia de Bonavía, 1996: 72. 
ingreso, las diferencias entre uno y otro producto son mínimas, aunque las que se tienen por la carne son más seguras, por las drásticas fluctuaciones del mercado. Si la crianza de camélidos sudamericanos de la microrregión se justifica más por la producción de carne, igual daría que sea de alpacas o de llamas; en sus condiciones de producción y tomando en consideración la demanda del mercado, estas últimas pueden resultar hasta más ventajosas que las anteriores.

Flannery, Marcus y Reynolds (1989), por referencia de Bonavia ${ }^{27}$, han encontrado que el período de gestación de la llama en las punas del norte de Ayacucho es de 10 meses y medio, una posibilidad que no se da en el caso de las alpacas, cuyas hembras paren, en promedio, en no menos de dos años. Los nacimientos en las llamas ocurren en la época plena puquy (de lluvias o de bonanza, entre enero y marzo), y con una mayor intensidad en el mes de febrero. Las llamas hembras paren a partir de los tres años de edad; a la misma edad, los machos son amansados para la carga. Cuando las llamas hembras paren, lo hacen en cualquier momento y sin ninguna intervención humana, pero las crías, cuando nacen, sí son objeto de un esmerado cuidado.

El valor de la llama radica principalmente en su capacidad de carga y transporte, después de amansada a los tres años. Hay familias asentadas en el piso ecológico suni que, entre los camélidos sudamericanos, sólo crían llamas y para utilizarlas en las faenas agrícolas, concretamente para el traslado de abono, herramientas y cosecha Las llamas más grandes y fuertes pueden transportar hasta 3 arrobas de peso, equivalente a 34,5 kg, y son las más aptas para los viajes largos. Las llamas de tamaño mediano constituyen la gran mayoría; como cargan menos, de 25 a $30 \mathrm{~kg}$, se les utiliza en el transporte interno y en los viajes cortos. Hay unidades domésticas que, a falta de llamas, utilizan la alpaca macho para el transporte interno y hasta para los qichwariy cortos.

Las razas o variedades de la llama son la qara (pelada) o kara y el chapu (lanudo); y, en la alpaca sólo se diferencia racialmente a la que es conocida como chili, que en otras regiones del país es llamada "suri", las demás son simplemente "alpacas" ("paqukuna"), no se les da el nombre de "wakaya". De las dos variedades de llama, se estima que la qara o kara llega al 70\% del total de llamas de la microrregión; y, la chapu, al 30\%. La llama kara tiene poco vellón en el cuerpo; carece de fibra en la cara, la cabeza y las piernas; posee un cuello largo y fuerte; tiene un perfil "acarnerado", con ojos grandes y mirada firme; tiene las extremidades firmes y fuertes; $y$, tiene un pelaje que cambia al concluir el año de edad y en diferentes tonalidades. Por su parte, la variedad chapu se caracteriza por tener un vellón abundante, denso, pesado y largo. Sus criadores le encuentran algunas semejanzas con la alpaca y la consideran menos resistente frente a las enfermedades y a la carga.

La tendencia de la llama macho a cruzarse con la alpaca hembra es mayor que aquella que ocurre entre una alpaca macho y una llama hembra. Al híbrido que resulta de ambos cruces se le conoce como "kuyru", y no se usa el término "warizo" o "wari", como en el sur del país. El kuyru puede ser cría de llama macho y de alpaca hembra (llamapa wawan, paqupa churin), o cría de alpaca macho y llama hembra (paqupa wawan, llamapa churin). El híbrido produce una "lana" (fibra) ligeramente más fina que la de la llama, y más resistente, y es utilizada para la confección de sogas y algunos tejidos gruesos; se dice que no hay nada mejor para la confección de sogas que la "lana" del kuyru. En las localidades huancavelicanas, y vecinas a la microrregión, el híbrido tiene dos denominaciones: wari, como en el sur del país, y "wakau”.

Sólo en Tucu, una localidad altoandina del distrito de Chuschi, los híbridos, entre las alpacas, son diferenciados por sus progenitores: el kuyru, de alpaca macho con llama

27 1996: 67. 
hembra; y, saqu, de llama macho con alpaca hembra ${ }^{28}$. El kuyru se parece más a la llama, por tamaño, fibra y hábito alimenticio, y su crianza es principalmente para la carne ${ }^{29}$. El $s a q u$, en cambio, se parece más a la alpaca y tiene las fibras gruesas y cortas, como para la confección de sogas (waskakuna), hondas (warakakuna) y frazadas (puñunakuna);

Lo que más diferencia a una alpaca de una llama es su dependencia frente al agua; a la dotación de este recurso natural se supedita su distribución espacial ${ }^{30}$. Cuando más fuentes de agua tiene un espacio altoandino, más amplia es la cobertura de su población alpaquera. Como la alpaca está siempre en búsqueda de sitios húmedos y pastos frescos hace que en su pastoreo sea transhumante y que las praderas nativas, una vez convertidas en bofedal (lliwapampa o "lliwal"), sean mantenidas verdes y, así, ampliadas; y, si no llegan a ser bofedales, por lo menos, regadas (qarpaykuspallapas).

Entre las alpacas hay una serie de diferencias, unas naturales, como la finura o el grosor y el color de la "lana", y otras que tienen que ver con las malformaciones físicas. No había hasta 1996, una diferenciación completa de las alpacas por raza, como en el sur del país, y se desconocían los términos "suri" y "wakaya". Se diferenciaba únicamente a la alpaca chili en los rebaños, principalmente por la delicadeza de su "lana". La alpaca chili es lo que en los departamentos sureños del país es la alpaca suri. Cuando se describe la "lana" de la alpaca chili se dice que es pesante, brillosa y lacia o menos enrulada y más larga. En la localidad de Churia, de la alpaca chili se extrae, cada 4 años, de 10 a 15 libras de fibra. No existe un término específico para identificar a las otras alpacas que no son de la variedad chili y que constituyen la gran mayoría; es decir, para las alpacas de lana "ensortijada", "enrulada" o "encrespada" y más corta, y que en el sur del país pertenecen a la raza o variedad "wakaya". Para estas alpacas no queda, en la microrregión, más que la posibilidad de identificarlas con el nombre genérico de la especie: paqu. Según la versión de uno u otro informante, a la alpaca llamada "wakaya", en el sur del país, y kupu, en Huancavelica, se la conocía antes como "brrutu" (así con doble r), una identificación que ya nadie utiliza. Hay alpacas de escaso tamaño y peso a las que se las conoce como "inchik", que, a los 4 ó 5 años, pesan apenas 20 kilos.

Otras diferenciaciones entre las alpacas son las concernientes al ciclo vital, que comprende tres etapas. Las dos primeras se determinan sólo por la edad, y la tercera, tomando en consideración, además de la edad, el sexo y la capacidad reproductiva. En las dos primeras etapas, las denominaciones sirven tanto para la hembra como para el macho. En la tercera etapa las denominaciones varían por sexo, y en las hembras, además, por capacidad reproductiva. Antes, no se acostumbraba vender ni matar a las mejores mamakuna (madres) ni a los mejores aywakuna (padres), se les mantenía hasta los 12 ó 15 años, sin que importara que ya tuvieran dentadura desgastada. Las mejores mamakuna eran las que daban crías año tras año, sin descanso; y, los mejores aywakuna, los que tenían mayor capacidad reproductiva, no sólo por la intensidad en el acto sexual, sino también por la efectividad en el "empreñamiento".

Los rebaños de alpacas mostraban hasta mediados de la década de los años noventa una fuerte propensión al coloreamiento; las alpacas blancas, por entonces, no alcanzaban ni la tercera parte. Hoy esta tendencia ha sido revertida, aunque el ritmo con que se da es todavía lento. Por los colores que tienen, las alpacas se clasifican en puras o enteras, combinadas y manchadas. Entre las puras o enteras se encuentran: yuraq, blanco; yana, negro; uqi, gris o plomo; chumpi o sani, café; habano, amarillo blanquecino; y, vicuña,

28 Machaca, 1991: 202.

29 Machaca, 1991: 205.

30 Bonavia, 1996: 73. 
color de la vicuña. Entre las combinadas, chañamuru o chanumuru, color entero chispeado con blanco o negro; chumpi qausu, marrón canoso; y uqi qausu, plomo canoso. Y entre las manchadas existen tres subclasificaciones: primero, por la predominancia entre dos colores claros y oscuros, por ejemplo el allqa, con predominancia del color claro; segundo, por la forma como se presenta un color sobre otro, por ejemplo el puka muro, con predominancia del blanco y pequeñas manchas que se aproximan al rojo; y, tercero, por la ubicación de un color sobre otro predominante, por ejemplo, qiqara, color entero claro u oscuro con mancha negra o blanca sólo en la frente. En la tercera subclasificación de las alpacas manchadas están también: wachwa, blanco de la cintura para adelante y negro de la cintura para atrás; yaku pisqu, cabeza blanca y cuerpo negro; kundurilla, cuerpo negro con una franja blanca en el cuello, como si tuviera puesta una chalina; Aparawasa, cuerpo blanco con dorso o lomo marrón, como si tuviera una montura puesta; chulla o qeulla, cabeza negra y cuerpo blanco; manguillas maki, brazos de color blanco; siwara, cuerpo blanco con mancha marrón o negra del dorso o lomo a la grupa.

Hay una serie de denominaciones en razón de las deformaciones o malformaciones físicas que presentan las alpacas. A las de ojos "zarcos", claros, las llaman qisru, "gringo" o "ringo"; a las que tienen más de dos pesuñas, llaqe o parqa; a las que siendo machos tienen un solo testículo, chiclón; a las jorobadas, muqu wasa, silla wasa; a las de cuello deformado, kuti; y, a las de orejas cortas, mutu.

La alpaca qisru, "gringo" o "ringo", dificulta al caminar y se muestra casi siempre dispuesta a tirarse (echarse) en las aguas estancadas (quchakuna) y permanecer allí largas horas, como indicando que quiere volver por una paqarina al uku pacha, el mundo de donde vienen las alpacas; para sus criadores, esta "costumbre" la hace más vulnerable frente a las enfermedades. En sus primeros años de vida, siendo uña (muy tierna) o malta (tierna), requiere un mayor cuidado de la madre; para unos, simplemente porque es "mañosa" y, para otros, porque sufre de ceguera. Por ciega, la alpaca qisru no puede caminar en medio de la nieve (riti). Según los criadores de alpacas, la existencia de una alpaca qisru en un rebaño significa "buena suerte"; es un premio que envía el Apu a quienes cuidan bien los rebaños de alpacas y llamas. Por considerarlas divinas, se esmeran por cuidarla más, en contra de lo que recomiendan los agentes externos de la promoción social, técnicos en ganadería altoandina: eliminarla por razones de selección.

Respecto a las otras alpacas con deformaciones y malformaciones físicas se dan muchas interpretaciones, de las que se dan cuenta solo algunas. Sobre la alpaca chiclón, se dice que sí procrea, en contra de lo que los agentes externos plantean. El testículo de este animal, por ser único, es considerado muy nutritivo para la alimentación humana; muere si se le castra. Sobre la alpaca kuti ("chueca") la información va en el sentido de que se la aniquila, si es que no es posible corregir la deformación o malformación, "si es que no se la endereza".

Llamar "lana" (millwa) a la fibra es una muy arraigada costumbre de los criadores de alpacas y llamas de la microrregión. Siguen siendo vanos los esfuerzos de los agentes externos de la promoción del desarrollo agropecuario por hacer que dejen de llamarla así, porque a diferencia de la lana típica es parcialmente hueca. Para sus criadores, "millwa" ("lana"), aycha (carne) y qara (piel) son los principales productos por los que crían la alpaca; "su lana es lana, y punto", diferenciar "lana" de "fibra" no les resulta todavía necesaria.

Se reconoce la existencia de tres clases de "lana" de alpaca: llasaq millwa ("lana" que pesa), chaupi millwa ("lana" media o intermedia), "lana normal" o chuya millwa ("lana" pura) y yaku millwa ("lana" de agua). La denominación de la primera clase de "lana" expresa categóricamente el criterio de peso; la de la segunda, parece dar a entender el peso, el tiempo de crecimiento y la calidad, (la lana podría ser "media" o "intermedia" en 
estos tres aspectos); y la de la tercera, hace una directa alusión a la pureza y a la calidad. Pero en la descripción que hacen los alpaqueros cualquier rasgo de calidad desaparece y sólo aparecen los criterios de peso y tiempo de crecimiento. En la llasaq millwa el peso es mayor porque la cantidad que se obtiene por animal es mayor y crece más rápidamente; en la chaupi millwa, el peso es normal o regular porque la cantidad por animal y el ritmo de crecimiento son los que se esperan, y en la yaku-millwa el peso es menor porque la cantidad por animal es menor y porque crece muy lentamente.

Un grupo de criadores de alpacas y llamas piensa que la cantidad y la calidad de la "lana" de alpaca varían según la raza del animal, aunque no precisan cuáles son las razas. Otro grupo sostiene que la cantidad y la calidad de la misma "lana" guardan relación con la cantidad y calidad de pastos que consumen las alpacas; el grupo anterior no cree que esta relación exista. No obstante, unos y otros coinciden en que hay una relación a la inversa entre el peso vivo del animal (en pie) y el peso de la "lana": cuando el peso vivo del animal es más, el peso de la "lana" es menos, y, a la inversa, cuando el peso vivo del animal es menos, el peso de la "lana" es más. Hay también quienes piensan que la cantidad y calidad de la "lana" dependen de la gordura del animal, que en el animal flaco la lana pequeña, crece difícilmente y es de baja calidad.

\section{El "león" y otros depredadores de la crianza}

El más peligroso depredador de la alpaca es el zorro, cuyos nombres en runa simi son atuq y uru. Este último también del gusano y del insecto. Sin ser tan perjudicial como el zorro, está también el puma entre los depredadores, más conocido como "león"31. El puma depreda todo tipo de animales, hasta los más grandes y fuertes como los equinos y vacunos, y el zorro, desde la llama hasta los animales menores. La presencia del puma no es frecuente ni numerosa; recorre los lugares como por turnos y ataca una sola vez; aprovecha sólo el seso y el corazón de su presa.

Los zorros atacan a las crías más que a las alpacas adultas. Cuando a falta de crías atacan a las adultas, lo que hacen es "prenderse del cuello, como un gato, hasta tumbarlas $y$ desmayarlas". Succionan primero la sangre, comen las vísceras y arrastran la carne a un lugar seguro para comerla por presas y en distintos momentos. Es difícil controlar la acción nociva de los zorros por la posibilidad que tienen de mimetizarse en medio del ichu (paja). Los zorros y las perdices (yutukuna), las aves más grandes con las que comparten el hábitat, tienen la coloración del ichu (de la paja); no necesitan correr mucho para, confundiéndose en el pajonal y evitar ser capturados. Los perros son los que se encargan de impredir la incursión de los zorros, guiados más por el olfato y por la audición que por la visión. Para erradicar a los zorros se aprovecha la costumbre que tienen de trasladar la carne del animal que atrapan hacia sus guaridas y de comerlas por presas y en distintos momentos; los pastores los siguen, rastreándolos, y rocían "suliman" (así llaman al veneno) en las porciones que encuentran. Se calcula que de un rebaño de 100 alpacas, de 10 a 15 son mortalmente atacadas por el zorro.

31 ¿Por qué los habitantes de la microrregión nombran a los animales salvajes conocidos con el de los que no conocen, como en el caso del puma, al que llaman "león"? Parece que la respuesta no está en ellos mismos, sino en aquellos que, al descubrir nuevas realidades, lo único que hicieron, para describir y clasificar lo desconocido, es aplicar, simplemente por semejanza, un vocabulario familiar, sin un adecuado cuidado por la concordancia. Cuando los europeos emprendieron la travesía atlántica hacia el oeste, no disponían "de un vocabulario descriptivo adecuado para su tarea, y estaba inseguro sobre cómo usar sus herramientas conceptuales en un terreno desconocido [...] los pumas eran leones, los jaguares tigres, etc." (Pagden, 1988: 31). 
No se sabe desde cuándo intervienen los perros en el pastoreo altoandino. Al referirse a la caza de los camélidos sudamericanos con la ayuda de los perros, Bonavia dice que hay indicios para pensar que "esta costumbre no se introduce en los primeros años de la Conquista, sino ya bien adentrados los tiempos virreinales, con perros de caza importados", y que no existen evidencias de que pudiera haber existido en tiempos prehispánicos ${ }^{32}$. Por ahora, no hay más que extender tales indicios hacia el pastoreo de los camélidos sudamericanos, si bien una acción contraria a la caza de los mismos, y pensar que pudo haber sido también otra costumbre "producto de conquista" y recordar un dato obtenido sobre la reciente historia del espacio altoandino del norte de Ayacucho que da acceso a la vertiente oriental: los hacendados acostumbraban dar perros de tamaño y fuerza especiales, llamados "chuli", a sus colones, para que con ellos, como un pago de renta por la tierra, protejan los rebaños que les encomendaban, de la acción depredadora de los zorros, "leones" y abigeos.

\section{La estancia como centro de crianza y residencia}

En el estudio de la formación social andina, hay un conjunto de palabras que se usan intensivamente sin una necesaria concordancia semántica. Cuando de ellas hay que mencionar las más conocidas, aparecen deslizándose por sí mismas las palabras "comunidad" y "ayllu"; y, si se impone una referencia específica a la formación social altoandina, se tiene que permitir la agregación de la palabra "estancia", cuya traducción al runa simi es hatus. Lo que estas palabras tienen en común, como las del conjunto, es el hecho de que se segmentan y parcializan en el uso, y como dificultan en cubrir semánticamente la totalidad de sus aspectos, se muestran como que no están implicadas con las incoherencias y los ocultamientos que se hacen alrededor.

La palabra hatus, que podría ser una deformación runa simi de la palabra castellana "hato", está ligada únicamente a la vida de los habitantes altoandinos o de puna (sallqa runakuna). Para estos habitantes de los Andes es el lugar que, por disponer de un conjunto de recursos naturales básicos, hace factible la permanencia de sus animales y, por esta razón, y casi únicamente por ella, su propia residencia. Implica, por un lado, un lugar determinado en el espacio sallqa (altoandino o de puna) y, por otro, el hecho de habitarla. El hatus ofrece dos condiciones de habitabilidad: uno permanente y otro temporal. Entre una y otra condición media la dotación de los recursos naturales básicos, principalmente de agua y de pastos, y complementada por dos aspectos que marcan la diferencia: la forma como los sallqa runakuna usan los recursos naturales básicos en provecho de sus animales, que es casi equivalente al pastoreo, y el tipo de vivienda que ellos mismos utilizan para estar junto a sus animales. En el hatus permanente, el pastoreo es sedentarizado y la vivienda es el hatus wasi (casa de estancia); y, en el hatus temporal, el pastoreo es, dentro de un marco sedentarizado, transhumante y la vivienda es apenas una chuklla (choza), precariamente construida. La "transhumancia es una forma de sedentarismo, ya que los movimientos de los pastores y sus rebaños, se llevan a cabo entre dos zonas conocidas y que son siempre las mismas" 33 .

El hatus temporal, al que en la microregión llaman astana (lugar de traslado y pastoreo) es utilizado y habitado en el período de lluvias, mientras el hatus permanente descansa para la recuperación de su carga botánica. Cuando los sallqa runakuna dicen que están en "pleno hatuschakuy" o "entre astana y astana" están haciendo un uso metafórico de la necesidad que

32 Bonavia, 1996: 610 y 611.

33 Bonavía, 1996: 530. 
tienen, en el período de lluvias, de construir una y otra choza y de desplazarse seguidamente de un lugar de traslado y pastoreo a otro lugar de traslado y pastoreo, respectivamente, para dar a conocer que están realizando pastoreo de transhumancia o "pastoreo de astana". Para esta variante de pastoreo sedentarizado, el desplazamiento de los miembros de la unidad doméstica no es total, es, apenas de uno o dos de sus miembros, por lo general del esposo o de una pareja de esposos. La permanencia en cada astana depende de la dotación de sus pastos, y ocupando una chuklla que apenas es para dos personas.

Entre las unidades sociales de la microrregión, que en proyección concéntrica van desde la unidad doméstica hasta la comunidad, pasando por el barrio o sector o la localidad, es la primera de estas dos últimas unidades sociales que se mencionan la que está íntimamente vinculada a la estancia y la que más la particulariza, y no hay razón para que no pueda ser usado el mismo término para que pueda ser identificada, antes que con los términos "barrio" o "sector".

Los habitantes de los espacios medio-andino (qichwa) y bajo-andino (yunka) con los que la microrregión mantiene una continuidad territorial de proyección vertical adscriben a sus unidades sociales altoandinas, globalmente, la categoría de "estancia" (hatus), y a sus miembros la identidad de estancieros, dando en ambos casos una primordial importancia a la ubicación sallqa (altoandina o puneña) que tienen. Si bien todas las unidades sociales de la microrregión están ubicadas en el espacio ecológico sallqa, no todas a las que están articuladas, y que son concéntricamente mayores, comparten el mismo espacio. Hay unidades sociales que pertenecen a otras, concéntricamente mayores, y que, además de los altoandinos, tienen espacios medio-andinos (qichwa) y bajo-andinos (yunga), y que le son, como dominio, externos. Donde esta situación se muestra en todas sus implicancias es en la localidad de Tuco, que además de pertenecer a la microregión, por su territorio puneño y su articulación económica, es parte de la antigua comunidad de Quispillaccta, que en una proyección vertical discontinua abarca un territorio de puna (sallqa) y otro de valle (qichwa y yunka). En el dominio territorial de la comunidad de Quispillaccta existen doce localidades, y de éstas la única que tiene la categoría de estancia es Tuco, por ser la única en su territorio puneño. Para los miembros de las once localidades de la comunidad de Quispillaccta ubicadas en el valle y que, atravesando el piso ecológico qichwa, llega hasta el piso ecológico yunka, estancia (hatus) es un espacio territorial de altura o puna, como el que tiene la localidad de Tucu, al que, por ser de vocación ganadera, todas tienen derecho de acceder.

Pero, esta visión externa que se tiene de la estancia varía de aquella que internamente se tiene en la microrregión. Para entenderla se tiene que tomar en consideración que su dominio territorial es totalmente altoandina o puneña y que, en consecuencia, ningún criterio respecto a ella resulta ser exterior. Su ubicación, y en proyección concéntrica, es específica: entre la unidad doméstica y la localidad. Su dominio no supera lo que en el espacio altoandino es lo interfamiliar o, en todo caso, lo vecinal, y para efectos de su identificación se utilizan el mismo término de estancia y los nuevos términos de "barrio" y "sector". Por esta ubicación que tiene es que en los estudios realizados en otras realidades de la formación social altoandina se dice que es "la unidad residencial mínima"34, y asociándola a la familia extensa.

Para Tristan Platt ${ }^{35}$ una estancia es un grupo de residencia patrilocal que se forma en la "puna", "en los márgenes de tierras cultivadas o tierras de barbecho" y donde rige la herencia de tierras. Surge, según el autor, con las asignaciones de tierras para el cobro

34 Ossio, 1992: 47.

35 1986: 37-51. 
estatal de tasas (tributo) entre los "indígenas", categorizados como "originarios, agregados y kantu runas". Precisa, además, que el "término tasa no sólo se refiere al impuesto que cobra el Estado, sino también al predio territorial cuyo control se hace posible por el pago del impuesto".

Si la estancia fue, como afirma Platt, el resultado de la integración de pagos (predios) y residencia de "indígenas", "originarios", "agregados" y "kantu runas" (hombres de la periferia o del extremo), significa que no todos sus ocupantes habrían estado emparentados consanguíneamente o que todas sus unidades domésticas habrían pertenecido a una sola familia extensa, posibilidad que se hubiera dado en caso la ocupación hubiera sido sólo de "originarios" y, tal vez, también de "agregados".

En la microrregión, la estancia o hatus tiene, como unidad social, casi la misma configuración captada por Platt en Potosí (Bolivia); sin embargo, no a todos sus integrantes les une el parentesco consanguíneo: Sus "originarios" son los que tienen el apellido más extendido o "principal"; sus "agregados" son los "vecinos" que llegaron con posterioridad, que a la larga resultaron emparentándose con los anteriores, por afinidad; y, sus "kantu runas", las unidades domésticas como las de las "warmisapakuna” (integradas sólo por mujeres, sin fuerza de trabajo varonil). Muy pocas estancias están en los márgenes de las tierras de cultivo con descanso localmente regulado (DLR) o barbecho sectorializado; pero, aun así no son locales, sino vecinales. La gran mayoría de las estancias están lejos de las tierras de cultivo, y en todos los casos tienen una configuración vecinal.

Dentro de las localidades, las familias fijan residencia en las estancias hatus (sociales), a los que recientemente se les llama también "barrios" o "sectores". De las dos o tres casas que tienen una familia nuclear dentro de la localidad, sólo el hatus wasi está habitado de modo permanente. Las casas que tienen en los centros administrativos y poblados, el hatun wasi (casa grande) y el llaqta wasi (casa de pueblo), son usados más como almacenes; o, de tener las localidades terrenos de cultivo, los habitan mientras dure la siembra o la cosecha.

Las estancias o los hatus ocupan los espacios periféricos que circundan los centros administrativos o poblados de las localidades. Aunque el asentamiento humano es disperso, hay en algunos pequeños agrupamientos de casas de estancia (hatus wasikuna), alrededor de un espacio libre y con corrales o dormideros (kanchakuna) en la periferia. Los hatus wasikuna son las de las familias nucleares que pertenece a una misma familia extensa; este rasgo hace que una estancia sea conocida como el lugar de residencia de aquellos que comparten un determinado apellido, por ejemplo: Wirkilla para los Gonzalo ${ }^{36}$, en Churia; u Occollopata para los Villanueva, Patacorral para los Palomino, Pampapunku para los Cancho y Quniqyaku para los Sosa, en Occollo ${ }^{37}$.

En la microrregión, la cantidad de estancias por localidad varía entre 3 y 12 , y la de familias por estancia entre 4 y 17 . Hay localidades en las que el crecimiento de las estancias es acelerado en los últimos 10 años, y Occollo es una de ellas. En 1996 esa localidad tenía 31 familias alpaqueras distribuidas en 5 estancias; en los años que han transcurrido, que son 13 , la cantidad de familias permanece casi igual, pero la cantidad de sus estancias se ha incrementado en más del doble. Las estancias aumentan con el desplazamiento de las residencias hacia las partes altas y alejadas de los centros poblados y con ventajas para el pastoreo. El apoyo técnico, gubernamental y no gubernamental, que reciben las unidades domésticas en el decenio que está por cerrarse y la existencia de pastizales no sobrepastoreadas vienen estimulando este desplazamiento.

36 Rojas, 1,997: 45.

37 Loayza, 1,999: 32. 


\section{Conclusiones}

Tomar la unidad doméstica como unidad básica de observación y análisis y un espacio microrregional altoandino como contexto social próximo son las dos determinaciones que más influyen en el contenido de los diez rubros que anteceden. En cada uno de ellos, conforme se los procesaba, han venido agregándose ideas que tienden a definir el sentido que comparten. Algunas de esas ideas, las de mayor influencia, aparecen a continuación, como conclusiones:

- Para las unidades domésticas altoandinas, la microregión es un espacio social concéntricamente mayor que muestra con mayor nitidez las implicancias de las relaciones que mantienen con el exterior, en tanto esas relaciones están marcadamente intermediadas por el mercado. A pesar de ser un escenario con una complejidad mimetizada en la simpleza y desnudez de su apariencia física, no deja de mostrar el orden y la jerarquía de sus instancias de organización y decisión social en una proyección concéntrica, a partir de la unidad doméstica y reproducidas (y transformadas) por la acción de los criadores de camélidos sudamericanos, principalmente.

- En una microrregión altoandina, entre las unidades sociales que, respecto a la unidad doméstica, son concéntricamente mayores, aquella a la que usualmente se adscribe el término "comunidad" es apenas una entre las de su tipo, vale decir, entre las unidades sociales campesino-comunitarias. En la proyección concéntrica que se abre a partir de la unidad doméstica, antes que la llamada "comunidad" está, por lo general, el barrio (sector o estancia), la localidad y el anexo de comunidad; y, después, el centro poblado menor y la misma microrregión. Todas estas unidades sociales, menores o mayores respecto a la unidad doméstica son, como ésta, unidades de decisión y organización que al reproducirse (y transformarse) mantienen sus respectivas autonomías, razón por la que no tienen la capacidad de reducirse totalmente entre ellas, por mayor que sean unas de las otras.

- La unidad doméstica, no obstante su conformación familiar y su carácter básico (elemental), es la que ejerce la centralidad de los procesos de reproducción (y transformación) de las unidades sociales de la formación social altoandina, una cualidad que se expresa en su condición ser, a la vez, unidad de producción y de consumo.

- Las relaciones de las que se vale la unidad doméstica para darse impulso son tanto familiares como sociales. Como no son únicamente familiares ni únicamente sociales, es de la confrontación de ambos tipos de relaciones que extrae ese impulso.

- La unidad doméstica, como unidad social, cumple la función de puente entre el contexto familiar y el contexto social. Se origina en el contexto familiar, y al resultarle este insuficiente, lo desborda y busca condiciones favorables en las unidades sociales concéntricamente mayores, que son cada vez más sociales y menos familiares. El carácter primordial y central que tiene obedece principalmente a este proceso.

- En la reproducción (y transformación) de las unidades sociales de una microrregión altoandina son decisivas, y con una marcada incidencia de la tradición, las relaciones entre los seres humanos, conformando grupos de distinta importancia y jerarquía; entre los seres humanos y la naturaleza, "patrimonio de los dioses"; $y$, entre los seres humanos y las divinidades, y con mediación de los animales, hoy principalmente de la alpaca.

- La intersección entre la reproducción y la transformación social, implicando tanto permanencia y cambio como tradicionalidad y modernidad, constituye un hecho inherente a la dinámica que siguen las unidades sociales de una microrregión altoandina, incluida, con un carácter básico, la unidad doméstica; y, entre las partes de la interacción ninguna es históricamente anterior o posterior, por no ser autosuficientes. 


\section{Bibliografía}

BONAVIA, Duccio

1996 Los camélidos sudamericanos. Una introducción a su estudio. Lima, IFEA$\mathrm{UPCH}$.

FLORES OCHOA, Jorge A.

1990 "Posibilidades del pastoreo altoandino". En: Jorge A FLORES OCHOA (coord.), Trabajos presentados al Simposio RUR 6. El pastoreo Altoandino: Origen, Desarrollo y Situación Actual. Cusco, 46 Congreso Internacional de Americanistas (Ámsterdam) - CEAC.

1988 "Mitos y canciones ceremoniales en comunidades de puna". En: Jorge A. FLORES OCHOA, Llamichos y paqocheros - Pastores de llamas y alpacas. Cusco, CEAC.

LOAYZA HUAMÁN, Severo

1999 Economía alpaquera y la organización social en la comunidad de OccolloAzabrán. Ayacucho, tesis de titulación.

MACHACA MENDIETA, Marcela

1991 Vigencia y continuidad de cultura y agricultura andina en Quispillaccta. Ayacucho, UNSCH-FCA-EFPA, tesis para optar el título de Ingeniero Agrónomo.

MARTÍNEZ ALIER, Juan

1973 Los huacchilleros del Perú. Dos estudios de formaciones sociales agrarias. Lima, IEP - Ruedo Ibérico.

OSSIO ACUÑA, Juan M.

1992 Parentesco, reciprocidad y jerarquía en los Andes. Una aproximación a la organización social de la comunidad de Andamarca. Lima, PUCP.

OSSIO ACUÑA, Juan y Oswaldo MEDINA GARCÍA

1985 Familia campesina y economía de mercado. Lima, CRESE.

ORTIZ, Alejandro

1989 "La comunidad, el parentesco y los patrones de crianza andinos". En: Revista Anthropologica, $\mathrm{N}^{\mathrm{0}}$ 7. Lima, PUCP.

PAGDEN, Anthony

1982/1988 La caída del hombre. El indio americano y los orígenes de la etnología comparada. Madrid, Alianza Editorial.

PLATT, Tristan

1986 "El rol del ayllu andino en la reproducción del régimen mercantil simple en el norte de Potosí (Bolivia)”. En: L.T. BRIGGS (et al.), Identidades andinas y lógicas del campesinado, pp. 25-83. Lima, Mosca Azul Editores - IUDED.

ROJAS, Julio

1987 Crianza de camélidos sudamericanos en la comunidad campesina de ChuriaRosaspampa. Ayacucho, tesis, UNSCH.

ROSTWOROWSKI DE DIEZ CANSECO, María

1988/1983 Estructuras andinas del poder. Ideología religiosa y política. Lima, IEP.

UBILLUZ GARCÍA, Percy

2003 "Identidad e intercambio entre pastores de camélidos en la cuenca del río Cachi". Ayacucho, UNSCH-FCS-EFPAS, Informe de investigación para el bachillerato. 